Orbis Tertius, vol. XXIV, ${ }^{\circ}$ 30, e131, noviembre 2019-abril 2020. ISSN 1851-7811

Universidad Nacional de La Plata

Facultad de Humanidades y Ciencias de la Educación

Centro de Estudios de Teorí a y Crítica Literaria

\title{
Capítulo (1967-1968): cómo contar la historia de la literatura argentina en una publicación de fascículos semanales
}

Capitulo (1967-1968): How to Tell an Argentine Literary History in Weekly Fascicles

Manuela Barral

Universidad de Buenos Aires, Argentina

barral.manuela@gmail.com

\section{RESUMEN:}

Entre agosto de 1967 y septiembre de 1968, aparece una de las primeras colecciones del Centro Editor de América Latina: Capítulo, la historia de la literatura argentina. Es una publicación de cincuenta y nueve fascículos semanales a la venta en kioscos de diarios y revistas de todo el país, de tirada masiva y precios bajos. Este trabajo caracterizará el modo de contar la historia de la literatura argentina de Capítulo en el marco de una política cultural de divulgación y ampliación del público lector. Se analizará: el plan organizado en serie de la colección, su diálogo con el soporte fascículo; los criterios de selección de los contenidos histórico literarios; y por último, qué idea hay sobre la periodización de la literatura nacional.

Palabras Clave: Proyecto editorial, Historia literaria, Centro Editor de América Latina.

\section{Abstract:}

Between August 1967 and September 1968, one of the first collections of the Centro Editor de América Latina appears: Capítulo, la historia de la literatura argentina. It is a publication of 59 weekly fascicles for sale in newsstands and magazines throughout the country, with mass circulation and low prices. This work studies its way of telling the Argentine literature history, in the framework of a cultural policy of dissemination and expansion of the reading public. The organization of the project as a planned series, its dialogue with the fascicle format, the selection criteria for literary and historical contents, and the way this project periodized Argentine national literature will be the main topics of this analysis.

KEYWORDS: Editorial project, Literary history, Argentina.

\section{De Eudeba al Centro Editor de América Latina}

Para empezar a hablar de Capitulo, la historia de la literatura argentina del Centro Editor de América Latina (CEAL) conviene hacer un desvío, o una escala previa, en la Editorial Universitaria de Buenos Aires (Eudeba), aunque eso signifique enumerar rápidamente hechos bien conocidos. En 1958 se fundó la Editorial Universitaria de Buenos Aires por iniciativa de su rector, Risieri Frondizi en el marco del gobierno desarrollista de Arturo Frondizi (1958-1962). ${ }^{1}$ Por recomendación de Arnaldo Orfila Reynal -a cargo del Fondo de Cultura Económica de México-, José Boris Spivacow fue designado como gerente general de la nueva editorial. Bajo el lema "Libros para todos", Spivacow impulsó desde el sector estatal una política cultural democrática y modernizadora, con el fin de difundir entre un público masivo libros de calidad a precios accesibles, además de editar el material bibliográfico y de investigación para los estudiantes y docentes universitarios.

Spivacow fue gerente de Eudeba durante ocho años. Después del golpe militar de Juan Carlos Onganía y de la intervención de las facultades nacionales, ${ }^{2}$ Spivacow y su equipo dejaron sus puestos de trabajo. Fue una renuncia a la empresa pero no al proyecto editorial de poner a disposición de un público popular y estudiantil libros baratos con contenidos de calidad. En efecto, el 21 de septiembre de 1966 comenzaron un nuevo proyecto editorial y cultural: el Centro Editor de América Latina (CEAL). ${ }^{3}$ Sin financiamiento estatal y desde el ámbito privado, Spivacow reformuló el lema de Eudeba -“Libros para todos”- por "Más libros para más”. Así lo corrobora José Luis de Diego, quien observa que "se ha debatido hasta qué punto las 
políticas de edición del CEAL constituyeron una continuidad respecto de Eudeba o cuáles fueron las líneas de diferenciación y de cambio" (2019, p. 166). Según el autor, por un lado, ambos proyectos coincidieron en el alto ritmo de producción, el bajo costo de venta y la difusión de sus publicaciones con una política cultural de ampliación del público lector; por otro lado, el proyecto de CEAL exhibió un mayor interés en las temáticas nacionales y latinoamericanas, y un proceso creciente de radicalización política e ideológica.

Entre agosto de 1967 y septiembre de 1968, apareció una de las primeras colecciones del CEAL ideada por Spivacow: Capitulo, la historia de la literatura argentina, ${ }^{4}$ dirigida por Roger Pla y bajo la coordinación general de Luis Gregorich. Capitulo fue una publicación pionera en la modalidad de venta de fascículos semanales. De tirada masiva y precios bajos, se distribuía en kioscos de diarios y revistas de todo el país. ${ }^{5}$ No solo fue novedosa la implementación de venta por fascículos sino también el tipo de circulación de una historia de la literatura argentina bajo este formato. Hasta 1967, se habían publicado tres historias de la literatura argentina: la primera, la Historia de la literatura argentina. Ensayo filosófico sobre la evolución de la cultura en el Plata de Ricardo Rojas, una obra monumental de ocho tomos, publicada entre 1917 y 1922. ${ }^{6}$ La segunda, la obra colectiva bajo la dirección de Rafael Alberto Arrieta Historia de la literatura argentina (1958), con foco "en la sucesión cronológica y la clasificación por géneros" (Santos, 2006, p. 65); y la tercera, Literatura argentina y realidad politica (1964) de David Viñas, una historia en la cual funciona "la discontinuidad como concepto" y "un estilo narrativo que descansa en las rupturas y las yuxtaposiciones violentas" (ibíd). Con respecto a Capitulo, es sabido que un móvil de la colección fue "formar al público" 7 y si bien no hay cifras exactas, ${ }^{8}$ no hay dudas de que fue un éxito de ventas. Con Capitulo se buscó difundir "la historia de la literatura argentina" de un modo ordenado en fascículos breves cuya composición apuntó a un lector masivo. En ese sentido, en la publicidad de lanzamiento se lee como premisa "Capítulo, la literatura argentina al alcance del pueblo" para intentar construir una cercanía entre un virtual lector popular y su comprensión de la historia literaria. Dice el texto completo de la publicidad:

Capítulo, la literatura argentina al alcance del pueblo: la vida de nuestros escritores, sus obras, los momentos más apasionantes de nuestra literatura. Una gran historia preparada por especialistas y dedicada a todos. Imprescindible para el hombre y la mujer que no quieren quedar al margen de la cultura, para el profesor, para el maestro, para el estudiante.

Los adjetivos que califican a esta historia de la literatura argentina como "imprescindible" y "apasionante" son una hipérbole publicitaria pero también exhiben el ingreso de un costado emocional para seducir y atraer al público masivo. Es posible leer la cercanía afectiva de una historia ofrecida "por especialistas" y "dedicada a todos" en donde lo dedicado connota el cuidado y la protección para que el lector evite "quedar al margen de la cultura". Por otro lado, esta conexión de los intelectuales "especialistas" con "el pueblo" caracterizado explícitamente como hombres, mujeres, estudiantes y maestros- en su enunciación trasluce una veta ideológica que bordea un paternalismo cultural.

Teniendo en cuenta lo precedente, este trabajo puntualizará algunos recursos de Capitulo para contar "la historia de la literatura argentina” en el marco de una política cultural de divulgación y ampliación del público lector del Centro Editor de América Latina. En primera instancia, se analizará el plan organizado en serie de la colección; en segundo lugar, se verá el diálogo con el soporte fascículo; tercero, se intentarán caracterizar los criterios de selección de los contenidos histórico-literarios; y por último, se rastreará qué ideas sobre el problema de la periodización literaria surgen y se discuten en este proyecto.

\section{Capítulo: La literatura argentina al alCanCe Del PUeblo}

Como indica el nombre de la colección, cada fascículo desarrolla un "Capítulo" de "la historia de la literatura argentina", e implica una relación de ida y vuelta entre la parte y el todo. Hay una articulación secuenciada y continua que es visible en la numeración sucesiva de cada fascículo. En total, son cincuenta y nueve fascículos de frecuencia semanal; cada uno de ellos de unas 28 páginas. La colección inicia sus 
primeras páginas en el fascículo $\mathrm{n}^{\circ} 1$ y cierra en la página 1416 del fascículo $\mathrm{n}^{\circ} 59$-un índice general de autores y obras-. Además, cada entrega es acompañada por un libro en formato pequeño que va integrando semana a semana la Biblioteca argentina fundamental, ${ }^{9}$ gesto que subraya la vocación del Centro Editor de América Latina por intervenir en el armado de bibliotecas en el espacio doméstico y constituir una comunidad de lectores.

Si desde el título combinado de la colección se cruzan la unidad y la totalidad, en la producción de los fascículos también está la tensión entre lo individual y lo colectivo. La redacción estaba a cargo de un equipo amplio de colaboradores -además del equipo responsable de su edición y diseño-. Por eso, cada fascículo consigna su propio título, su autor y explicita en todos los casos la revisión de Adolfo Prieto. La enumeración de sus redactores permite ver cómo el Centro Editor de América Latina reunió críticos de diversas trayectorias. Hacia 1967, algunos autores ya tenían una trayectoria intelectual: Augusto Raúl Cortázar, Bernardo Canal Feijoo, Guillermo Ara, Raúl H. Castagnino, Carlos Mastronardi, Horacio Jorge Becco, Héctor René Lafleur, Attilio Dabini y Gregorio Weinberg; otros la iban consolidando: Adolfo Prieto, Noé Jitrik, Horacio Jorge Becco, Félix Weinberg, Luis Ordaz, Rodolfo A. Borello, Alfredo Veiravé, Rodolfo Vinacua y Elvira Burlando de Meyer; y por último, Capitulo también fue un semillero de jóvenes que serán luego fundamentales para pensar la renovación de la crítica literaria especializada. Entre ellos, Andrés Avellaneda, Beatriz Sarlo, Jorge Lafforgue, Nora Dottori, Jorge B. Rivera, Eduardo Romano y Susana Zanetti (quien dirige la segunda edición de la colección, en 1979-1980).

Tanto por su autoría individual como por su unidad temática, cada uno de los cincuenta y nueve fascículos funciona de forma autosuficiente y abarca un estudio sobre un género, período o autor determinado. A la vez, se establece una continuidad a lo largo de la colección por una pauta cronológica que va desde la Conquista y la Colonia hasta quienes están produciendo literatura mientras se escribe esta historia. Por ejemplo, el fascículo $n^{\circ} 58$ se titula "El mapa literario" e incorpora a "Las últimas promociones (nacidos después de 1930)" entre quienes se encuentran las escritoras y los escritores: Abelardo Castillo, Griselda Gambaro, Sara Gallardo, Juan José Saer y Tununa Mercado. ${ }^{10}$ Otro de los últimos fascículos -Capítulo no 56 - está dedicado a las revistas literarias y presenta un listado de publicaciones contemporáneas tales como El Escarabajo de Oro (1958), Hoy en la Cultura (1961), El Barrilete (1963), Actitud (1963), Cuadernos de Crítica (1964) y Yunque (1965). En ese sentido, Susana Santos propone que: "esta operación crítica distingue a Capítulo de las anteriores historias de la literatura como la de Ricardo Rojas, Arrieta y aun David Viñas cuyo recorte concluye, con parsimonia, precisamente frente a sus contemporáneos" (2006, p. 70). ${ }^{11}$ Por otra parte, los sugestivos tres puntos suspensivos de "Los contemporáneos 1940- (...)" pueden asociarse con el "continuará" insistente que supone la colección en su secuencia de editar con regularidad un fascículo tras otro. En línea con esa preocupación por los circuitos de distribución y acceso, de Diego registra otra diferencia con respecto a las historias de Rojas y Arrieta: aquellas "tenían un perfil académico y estaban orientadas a una clase ilustrada con competencias formadas en la universidad. En este caso, el modo de comercialización, el fácil acceso y la amplia difusión lograron poner en manos de muchos, a la vez, una historia en fascículos y una biblioteca, sin ceder en el necesario rigor crítico e histórico del proyecto" (2019, p. 172).

Ahora bien, ¿cómo cuenta la historia de la literatura argentina Capitulo, sin ceder en el rigor crítico e histórico? ¿Es posible leer el éxito de ventas en sus procedimientos discursivos y retóricos? ¿En qué se sostiene la realización efectiva de su programa cultural de divulgación?

\section{III. "EL PLAN DE LA OBRA"}

Para reflexionar sobre el modo de difusión de Capitulo, la historia de la literatura argentina ayuda describir "el plan de la obra" -así es anunciado en las contratapas de los primeros veinticuatro fascículosque organiza la colección. Este plan es el pilar fundamental que sostiene el peso del ambicioso planteo de sus 
cincuenta y nueve fascículos: sistematizar la historia de la literatura argentina "al alcance del pueblo". El afán pedagógico se manifiesta en una rigurosa organización que abarca un período de cuatrocientos años, es decir, un gran volumen de datos literarios, históricos, políticos y culturales metabolizados para un lector no especializado. En ese sentido, los tres primeros fascículos ("Los orígenes (1536-1880)", "El desarrollo (1880-1940)" y "Los contemporáneos (1940-...)" son representativos de la forma global que adquiere el plan de edición. Los tres fueron escritos por Roger Pla, el director de la colección, y juntos funcionan como introducción y condensación sintética de los temas y contenidos que se desarrollarán a lo largo de la obra.

Según cuenta Luis Gregorich, el secretario de redacción: "El plan fue diseñado por el escritor y crítico Roger Pla, designado director de la obra, y el profesor universitario Adolfo Prieto, especialista en literatura argentina. A la vez fui convocado como coordinador general $\left(2018\right.$, p. 1). ${ }^{12}$ En la elección de los títulos se evidencia cómo el relato de la historia de la literatura argentina que planifica Roger Pla va unido a los contextos de producción, es decir, a las condiciones materiales históricas y sociales de producción de los textos. Una muy breve enumeración de algunos títulos en correlación con los contenidos de cada volumen ejemplifica cómo ingresan las condiciones históricas de posibilidad de los textos en cada fascículo: en el no 4, "Época colonial: del Renacimiento al Barroco", su autor, Bernardo Canal Feijoo, relaciona la aparición de Luis de Tejada como primer poeta argentino con la conquista espiritual, proceso central de la "época colonial", en el siglo XVIII (1967, p. 89); en el no 13, "El ensayo en la época romántica", Adolfo Prieto sintetiza: “Alberdi después de Caseros. Elección y parábola de la soledad” (1967, p. 300) y explica la producción de su autor por la coyuntura histórica de Caseros; en el fascículo no 53, "La narrativa: la generación del 55", Luis Gregorich vincula a "Los narradores del 55 y el peronismo" y sugiere "ver de qué manera concreta aparecen las figuras humanas y las situaciones del régimen peronista en las novelas y relatos de estos escritores" (1968, p. 1249). La referencia al "fondo histórico" (Jitrik, 1967, p. 208), "marco histórico" (Sarlo, 1967, p. 385), “la época” (Sarlo, 1968, p. 769), "fondo histórico y social” (Gregorich, 1968, p, 1250), “ámbito histórico y social” (Delgado, 1968, p. 1297), puede rastrearse y corroborarse en algunos fascículos de otros autores. Aunque sea un detalle nimio, la falta de criterio unificado entre los autores acerca de cómo nombrar el contexto de producción exhibe que esta pauta no resulta homogénea a lo largo de los distintos "capítulos". Esto ilustra el trasfondo teórico de revisión de las relaciones entre base y superestructura, a partir de las lecturas de Antonio Gramsci que los intelectuales argentinos marxistas estaban haciendo en el marco de la renovación de las ciencias sociales de los años sesenta.

El no 1, “Los orígenes (1536-1880)", anticipa lo que será desplegado en los fascículos entre el no 4 y el $\mathrm{n}^{\circ}$ 23. Este fascículo contiene mayoritariamente términos que remiten a hechos -tal y como los designaba la historiografía política- para titular los distintos artículos que lo componen (por ejemplo: "La colonia", "La independencia política”, "La Revolución de Mayo"). En él se homologa la independencia política a la independencia literaria ("Las nuevas generaciones sentirán, ya hecha conciencia la separación política con España y la consumación en marcha de nuestra independencia, que es preciso sacudir este sometimiento cultural" (Pla, 1967a, p. 13)). Pla postula que en este largo período que va desde la Conquista hasta la generación del ochenta predomina un "tono épico" cuyo rasgo principal es la supeditación de la literatura a los grandes ideales colectivos y a lo histórico político.

El no 2, "El desarrollo (1880-1940)", sintetiza lo que se tratará en los fascículos desde el no 24 hasta el $\mathrm{n}^{\circ}$ 41. Según Pla, este período se caracteriza por estar signado por un tono lírico y subjetivo, en el que la literatura tiende a centrarse en sí misma a través de los grandes movimientos estéticos como el modernismo, el ultraísmo, el martinfierrismo. En este recorte también se incluye el realismo y el naturalismo de los sectores de izquierda -representados por "El grupo Boedo" (1967b, p. 40)-, a los cuales se distingue por su concepción de la literatura bajo premisas sociales y políticas. En estos fascículos figuran algunas referencias a grandes acontecimientos de la historia de occidente (el inicio del siglo XX, la guerra y la posguerra).

Por último, el fascículo $n^{\circ} 3$, "Los contemporáneos (1940-...)", abarca lo que será narrado en los fascículos $n^{\circ} 42$ a n ${ }^{\circ}$ 59. Para Pla, este período se identifica por la consolidación de la narrativa de escritores en su 
singularidad. Al respecto, esboza un argumento acerca de la ausencia de grupos de pertenencia: la literatura se volvería una cuestión individual, expresada "con fuerte acento de lo personal y autobiográfico, hasta el punto que cada uno de los escritores más representativos de este período debe ser estudiado por separado, sin que sea posible agruparlos en un mismo movimiento ideológico, estético o siquiera en una capilla literaria" (1967c, p. 72).

La estrategia de los tres primeros fascículos escritos por Roger Pla es, así, doble: se tienta al público lector con una síntesis que funciona como lo que hoy llamaríamos booktrailer, y al mismo tiempo, se da una visión de conjunto y se explicita ordenadamente el funcionamiento del plan diseñado, la sólida estructura sobre la cual se erigirán los restantes fascículos. Porque si bien es posible imaginar que la escritura de los fascículos por los distintos autores estuvo atravesada por los tiempos erráticos del periodismo y la urgencia de los plazos para cumplir con las entregas semanales, también se advierte al leer las contratapas y los índices que los acompañan la existencia de un plan que, semana a semana, muestra sus costuras y dialoga sugestivamente con sus lectores en tanto disparador del deseo de completar la colección, sin perder ningún "capítulo" para comprender este dispositivo cultural de transmisión de la historia de la literatura argentina.

Asimismo, estos hilos organizativos se articulan con el soporte y los recursos gráficos. En las contratapas de los primeros fascículos, muy brevemente, se expresa el plan de la colección con tono publicitario: "Capitulo constituirá, a través de sus 56 (sic) fascículos, una Historia de la Literatura Argentina, ordenada cronológicamente desde la Conquista y la Colonia hasta nuestros días. El material gráfico con que se ilustrará la Historia, estrechamente vinculado con el texto, brindará a los lectores una visión viva y amena de literatura y del país". Esa "visión viva y amena de la literatura” enfatiza ese carácter liviano y accesible, que se apoya en el material gráfico que da una gran importancia a la reproducción de las tapas de los libros y los escenarios de las obras literarias analizadas, lo cual funciona, a su vez, como material didáctico a docentes y estudiantes. El diseño visual de la colección corresponde a Oscar Díaz, ${ }^{13}$ jefe de arte del CEAL. Según se indica en cada ejemplar, los recursos gráficos provienen de colaboraciones del Archivo Gráfico de la Nación, de la Biblioteca Nacional y de museos nacionales. La estrategia visual de las tapas y contratapas diseñadas por Oscar Díaz es muy colorida - con colores fuertes como fucsia, azul, verde y letras negras-, y se suman ilustraciones centrales que ocupan casi la totalidad de las tapas. En general, las tapas reproducen retratos de los autores en gran tamaño, con un diseño atractivo y llamativo. Además, las contratapas son utilizadas como carteleras. Allí se informa qué libro acompaña al fascículo y se anuncian las próximas entregas interpelando al lector: “iNo se las pierda!”.

Mientras que las tapas coloridas son pensadas para ser exhibidas en kioscos callejeros, el interior de los fascículos es discreto y austero, en blanco y negro. En la mayoría de los casos, las páginas están organizadas a dos o tres columnas, para facilitar la lectura. Los textos se acompañan de ilustraciones y fotografías, con un diseño despojado de líneas y recuadros para separar los contenidos. El mismo objetivo se advierte en el uso de subtítulos y recuadros que destacan ciertas informaciones o brindan datos adicionales. Este aspecto puede asociarse con la idea de un lector no especializado a quien hay que guiar entre la información presentada con textos breves y recuadros ordenadores. Resulta interesante que el primer texto con que comienza esta historia, en el fascículo "Los orígenes (1536-1880)", dice: "En estas páginas el lector verá desfilar a partir de los primeros capítulos esta Historia Ilustrada de la Literatura Argentina todo el panorama de nuestra vida espiritual como ha quedado fijada en las obras de nuestros escritores". Es decir que se alude al lector como un observador de una historia que, al menos en ese primer fascículo, es rebautizada como ilustrada (Pla, 1967a, p. 1), subrayando la importancia que se atribuía a los apoyos visuales en el plan general de la obra. Acaso para que el lector pueda ver - una operación sensorial más inmediata que leer-ese desfile literario diseñado por Capitulo. 


\section{CRiterios de SELEcción de los CONTENidos históRICO-LITERARIOS}

Primero, se puede obtener una mirada panorámica de la selección de temas literarios e históricos de Capitulo, la historia de la literatura argentina a partir de la lectura del índice general y los distintos títulos de los fascículos. Pero para comprender cabalmente cuáles son los criterios de selección de los contenidos histórico-literarios que organizan el proyecto, es necesario atender a cómo se establece el cruce entre los términos literarios y los términos históricos en esta historia de la literatura argentina. Para ello, es clave el texto que escribe Roger Pla en el fascículo no 3 "Los contemporáneos (1940-...)" titulado: "El problema de los períodos en la historia de la literatura”. Su reflexión inicial acerca de cómo opera la historiografía de la literatura podría ser una síntesis para pensar los criterios de selección de los contenidos de Capítulo:

La división en períodos, y la justificación correspondiente de esta división, es uno de los problemas más arduos de la historia de la literatura. Algunos especialistas subordinan las épocas de una literatura determinada a hechos históricos o sociales del país en que se ha producido (1); otros, proponen identificar esas épocas con las etapas de evolución del idioma que constituye la fuente nativa de la literatura tratada (2); otros, con la sucesión de las distintas escuelas o corrientes estéticas (3), y no ha faltado quien se limitara a centrarla en las figuras más representativas de cada época, estudiándolas inclusive con un tratamiento psicológico o biográfico (4); otros, en fin, hablan más bien de generaciones que de períodos y hacen fincar el desarrollo de una literatura nacional en las sucesivas hegemonías de cada una de esas generaciones, formadas respectivamente en ámbitos culturales, sociales y políticas más o menos homogéneos (5) (1967c, p. 72).

Aunque sea de un modo esquemático, vale la pena detenerse en este párrafo para pensar en los puntos de anclaje del conjunto de los fascículos.

1. Subordinación de lo literario a lo histórico. Los primeros fascículos de Capitulo (del $\mathrm{n}^{\circ} 4 \mathrm{al} \mathrm{n}^{\circ}$ 9) se organizan nominalmente en función de los acontecimientos históricos políticos y sociales -aunque no necesariamente se da una relación de subordinación, más bien esto es puesto en cuestión-. El n ${ }^{\circ} 4$ se titula "Época colonial: del Renacimiento al Barroco"; el n 5 "Época colonial: la ilustración y el seudoclasicismo", el no 6 "La época de Mayo". En el primer texto del fascículo $n^{\circ} 1$ "Los orígenes" afirma Roger Pla: "pensar en nuestra literatura es pensar en la biografía del espíritu de nuestra misma nación. Por eso la historia de nuestra literatura no es otra cosa que la historia de nuestra biografía nacional" (1967a, p. 2). Esta afirmación de Pla parecería llevar en dirección de una unicidad nacionalista, signada por la idea de una única biografía nacional, ajena en términos literarios a los regionalismos y las literaturas en lenguas indígenas. No obstante, de ninguna manera esa frase de Pla marca la pauta historiográfica de Capitulo. En este punto, se vuelven visibles las diferencias entre aquello planificado previamente en el plan de edición y el abordaje de cada fascículo por autores diversos que a veces con sus textos proponen otras perspectivas. Por ejemplo, en el Capitulo no 9 “Echeverría y la realidad nacional”, Noé Jitrik, autor del fascículo, afirma elocuentemente los matices vinculares entre lo histórico y lo literario: "Como siempre, el tiempo histórico envuelve al hecho temporal de valor literario. Ninguno de los dos es la clave de la explicación del otro. Cada cual se explica a sí mismo. Pero ambos se iluminan y se corresponden secretamente sin disminuir en nada su realidad intrínseca” (1967, p. 201).

2. Idioma nacional. En Capitulo son acotados los casos que analizan el vínculo del idioma con la producción literaria. En el fascículo no 1 , Pla escribe un artículo denominado "El idioma nacional". En él afirma que "El estudio de la literatura argentina no puede emprenderse como sería imposible estudiar, por lo demás, ninguna literatura nacional en el mundo- sin una correspondiente referencia al idioma que le dio base y sustento vital” (1967a, p. 7). Esta afirmación sólo queda asentada en la introducción sin ser luego desplegada en los fascículos, salvo por una alusión aislada de Adolfo Prieto sobre Esteban Echeverría y su relación con "la obligada herencia del idioma español” (1967, p. 298). Así, el lugar del idioma nacional no parecería constituir un criterio de selección en Capítulo. 
3. Movimientos estéticos. Hay varios fascículos destinados íntegramente a caracterizar movimientos estéticos. Entre ellos: el naturalismo ( $\left.{ }^{\circ} 22\right)$; el modernismo ( $\left.\mathrm{n}^{\circ} 25\right)$; la picaresca ( $\left.\mathrm{n}^{\circ} 28\right)$; el sencillismo ( $\left.\mathrm{n}^{\circ} 36\right)$, el realismo ( $\left.\mathrm{n}^{\circ} 37 \mathrm{y} \mathrm{n}^{\circ} 38\right)$. En los diversos artículos de estos fascículos predominan los términos literarios, y este abordaje no recela del ingreso de la historia. Esta diferenciación se vale de una clasificación global de los movimientos estéticos que se desglosa en ejemplos representativos de autores y sus obras literarias. Esta organización es simple metodológica y conceptualmente, es ordenada y funcional al carácter didáctico del "plan de la obra”.

4. Figuras de escritores. Hay varios fascículos que se concentran exclusivamente en un escritor:

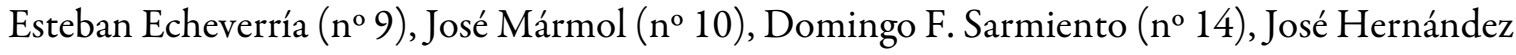
$\left(n^{\circ} 16\right)$, Lucio V. Mansilla ( $\left.{ }^{\circ} 18\right)$, Miguel Cané y Eduardo Wilde ( $\left.{ }^{\circ} 21\right)$, Almafuerte $\left(n^{\circ} 24\right)$, Leopoldo Lugones ( $n^{\circ} 26$ ), Roberto J. Payró ( $n^{\circ} 28$ ), Ricardo Güiraldes ( $\left.n^{\circ} 30\right)$, Roberto Arlt ( $n^{\circ} 42$ ), Ezequiel Martínez Estrada ( $\left.n^{\circ} 44\right)$, Eduardo Mallea ( $\left.n^{\circ} 46\right)$, Leopoldo Marechal ( $\left.n^{\circ} 47\right)$, Jorge Luis Borges ( $n^{\circ} 48$ ); y una única escritora: Alfonsina Storni ( $\left.n^{\circ} 34\right)$. Como modo narrativo, se destaca el recurso de incorporar elementos biográficos para estudiar las obras de los autores. Por ejemplo, Noé Jitrik analiza la "Relación vida-obra” de José Hernández y el Martín Fierro en el Capitulo no 16.

5. Generaciones. En Capitulo la noción de generación funciona como criterio ordenador de varios fascículos. Por ejemplo: "La segunda generación romántica: la poesía" ( $\left.\mathrm{n}^{\circ} 17\right)$, "La generación del ochenta: las ideas y el ensayo" ( $\left.\mathrm{n}^{\circ} 19\right)$, “La poesía: la generación del “40” ( ${ }^{\circ}$ 49), "Desarrollo de la narrativa: la generación intermedia” ( $n^{\circ} 51$ ), "La narrativa: la generación del $55^{\circ}$ " (n 53). Llama la atención la falta de problematización de este concepto. Tal vez se deba a que se privilegia su valor didáctico; aunque en ese sentido también es extraño que no se refiera en los fascículos que José Ortega y Gasset ya había propuesto a principios de los años veinte un procedimiento de estudio social basado en las generaciones ${ }^{14}$

En cuanto a la periodización literaria, Roger Pla reflexiona sobre este problema en su texto "El problema de los períodos en la historia de la literatura":

Lo que importa, según parece evidente, es que tal división pueda aplicarse a la propia literatura, que represente cambios y evoluciones vinculados a la misma estructura literaria, y no, arbitrariamente, movimientos generacionales, políticos e históricos que, con ser muy importantes, no signifiquen a su vez un cambio en la historia misma de la literatura. La poesía de la revolución sigue siendo neoclásica, exactamente como lo venía siendo en la época virreinal (1967c, p.72, subrayado nuestro).

En ese fragmento hay una pregunta subyacente, un interrogante que incluye una formulación crítica: ¿cómo establecer modos de periodización específicos de la propia literatura, de la misma estructura literaria que remitan a la historia misma de la literatura? En Capitulo, la bistoria de la literatura argentina la periodización histórico literaria se aborda en su complejidad y apunta a encontrar su autonomía conceptual, sus propios parámetros de análisis. Incluso es posible pensar que por su colocación al comienzo de la colección, el artículo "El problema de los períodos en la historia de la literatura", tiene una intención programática. 15 En la misma línea, en el fascículo "La crítica literaria moderna" a cargo de Rodolfo A. Borello ( $\mathrm{n}^{\circ}$ 45), se mencionan las historias de Ricardo Rojas y Rafael Arrieta. En ambos casos, Borello objeta la falta de especificidad de estas historias para analizar y periodizar lo literario. Mientras que critica de Rojas lo acotado de su "visión histórico-documental de lo literario" (1968, p. 1058), del volumen dirigido por Arrieta señala que "continua una periodización de nuestras letras demasiado atada a lo político, con una metodología confusa y en general muy poco rigurosa" (1968, p. 1076). Estos reparos muestran la consciencia metahistoriográfica de algunos autores de la colección. 


\section{Conclusiones}

El modo de contar la historia de la literatura argentina de Capitulo en sus fascículos semanales comprende dos operaciones superpuestas. Está la estructura general de la obra, expresada en la información que circula en las contratapas, sus publicidades, y que se desprende al recorrer los títulos de los fascículos y sus artículos en los índices generales. Es decir, es el "plan de la obra" que busca exhibirla como unidad, de la mano de una estrategia de divulgación sostenida en la idea de una historia de la literatura argentina "al alcance del pueblo". En la publicidad de lanzamiento de Capitulo se incluye el slogan: "Todo el país a través de toda su literatura". Así, con una vocación totalizante e inclusiva, inscribe a Capitulo en la política cultural democrática y modernizadora que Spivacow había iniciado en Eudeba con el fin de difundir entre el público masivo libros de calidad a precios accesibles. En sintonía, en las coloridas contratapas de los últimos veinticinco fascículos de Capitulo se lee: "Todas las semanas Capitulo le ofrece la más moderna e ilustrada Historia de la literatura argentina y una obra completa y representativa de la Biblioteca argentina fundamental'. Semana a semana, la misma frase invita a su público a re-pactar el acuerdo de la serie y su promesa de continuidad.

En simultáneo, ese plan macro habilita la convivencia de visiones divergentes entre sus distintos autores. Según quién escriba la historia, predominan formas del estudio biográfico acerca de los escritores, mayor o menor énfasis en la relación vida-obra, o bien se alterna en un análisis crítico de los contextos de producción y la ubicación histórica o se esboza una relación causal de subordinación. Los vaivenes en el modo de contar la historia de la literatura argentina en Capitulo dejan entrever las discusiones ideológicas y teóricas entre los "especialistas" a cargo de su redacción. Esta zona de disputa historiográfica muestra que el abordaje de la historia de la literatura argentina de Capitulo no es homogéneo. Por un lado, hay académicos con una formación histórica más clásica; por otro lado, hay nuevos intelectuales que escriben desde sus reflexiones acerca del lugar de la cultura en relación con sus condiciones de posibilidad desde una perspectiva de izquierda. Capitulo es una historia colectiva y heterogénea en su composición -aun contradictoria- donde conviven diversas tradiciones teóricas e historiográficas, sin perder el "plan de la obra" de "la más moderna e ilustrada Historia de la literatura argentina".

Asimismo, es importante subrayar que el entramado relacional es puesto en primer plano; sobre todo, entre las obras literarias: "esta Historia no se propondrá otra cosa que estudiar las obras en sí mismas, en sus significados y sus formas, dentro de la relación que pueda darse entre ellas y el contexto histórico donde se producen" (Pla, 1967c, p. 72). Capitulo, la historia de la literatura argentina concluye su colección con el fascículo $n^{\circ} 58$ "El mapa literario". Es un fascículo prolijamente organizado con tablas de doble entrada ordenadas en tres etapas ("I-Desarrollo de los géneros literarios (1536-1880)", "II-El desarrollo, la madurez nacional (1880-1940)”, III-“Los contemporáneos (1940-...)”. Este mapa sintetiza, integra y abre -con esos tres puntos suspensivos finales que no cierran- de un modo muy esquemático y relacional la historia de la literatura argentina que compone Capitulo. En la misma línea, el último libro de la Biblioteca argentina fundamental es el Diccionario básico de la literatura argentina redactado por Adolfo Prieto. En suma, si desde el título combinado de la colección se conjugan la serialización (los fascículos/capítulos) con una idea de obra completa ("la historia de la literatura argentina"), no parece casual, entonces, que tanto Capitulo, la historia de la literatura argentina como la Biblioteca argentina fundamental concluyan con las imágenes del mapa y del diccionario, que también se apoyan en un sistema codificado en donde el engranaje y el orden de las partes articula el conjunto mayor. Lo mismo sucede en el funcionamiento analizado de la Historia de la literatura argentina, cuyos fascículos breves, de diseños atractivos e ilustrados, favorecen la consulta y el acceso del público lector. Aunque, por suerte, por mayor rigor metodológico o historiográfico involucrados, ninguna clasificación interna podrá controlar cómo cada lector elige leer. 


\section{ReFERENCIAS}

Borello, R. (1968). Ricardo Rojas y el historicismo nacionalista. Capitulo, 45 "La crítica moderna", junio, pp. 1058-1068.

Canal Feijóo, B. (1967). Siglo XVIII: el primer poeta argentino: Luis de Tejeda. Capitulo, 4 "Época colonial: del Renacimiento al Barroco", septiembre, pp. 89-94

Dalmaroni, M. (2006). "La providencia de los literatos": escritores argentinos y Estado durante la modernización (1888-1917). Iberoamericana (2001-), Nueva época, año 6,21, pp. 7-24.

De Diego, J. L. (2019). Los autores no escriben libros. Nuevos aportes a la historia de la edición. Buenos Aires, Argentina: Ampersand.

De Diego, J. L. (2014). La 'época de oro' de la industria editorial. En J. L. de Diego (dir.), Editores y políticas editoriales en Argentina (1880-2000). Buenos Aires/ México: Fondo de Cultura Económica, pp. 91-124.

Delgado, J. (1968). Ámbito histórico social: el país después de 1960. Capitulo, 55 "Las nuevas promociones: la narrativa y la poesía", agosto, pp. 1297-1299.

Delgado, V. (2015). Algunas cuestiones críticas y metodológicas en relación con el estudio de revistas. En Delgado, Mailhe, Rogers (coord.), Tramas impresas. Publicaciones periódicas argentinas (XIX-XX). La Plata, Argentina: Editorial FaHCE, pp. 11-25.

Fernández, O. (2006). Eudeba: el papel del estado en la edición de libros en la Argentina (1958-1980). En M. Bueno y M. A. Taroncher (coord.), Centro editor de América Latina. Capitulos para una historia. Buenos Aires, Argentina: Siglo XXI, pp. 39-61.

Gociol, J. (comp.) (2007). Más libros para más. Colecciones del Centro Editor de América Latina. Buenos Aires, Argentina: Biblioteca Nacional.

Gociol, J. (comp.) (2012). Libros para todos. Colecciones de EUDEBA bajo la gestión de Boris Spivacow (1958-1966). Buenos Aires, Argentina: Biblioteca Nacional.

Gregorich, L. (2018). A cincuenta años de un gran capítulo. La Nación, 3 de junio de 2018. Recuperado de https://w ww.lanacion.com.ar/opinion/a-50-anos-de-un-gran-capitulo-nid2139746, consultado el 8 de agosto de 2019.

Gregorich, L. (2012). Spivacow y la fábrica de libros. La Nación, 19 de julio de 2012. Recuperado de https://www.lan acion.com.ar/cultura/spivacow-y-la-fabrica-de-libros-nid1490902, consultado el 8 de agosto de 2019.

Gregorich, L. (1968). Los narradores del 55 y el peronismo. El fondo histórico y social. Capitulo, 53 "La narrativa: la generación del 55", junio, pp. 1249-1252.

Jitrik, N. (1967). Echeverría y la realidad nacional. Quién es Echeverría: su biografía. La obra literaria. Fondo histórico de La cautiva. Capitulo, 9 "Echeverría y la realidad nacional”, octubre, pp. 193-201.

Maunás, D. (1995). Boris Spivacow. Memoria de un sueño argentino. Buenos Aires, Argentina: Colihue.

Merbilhaá, M. (2014). 1900-1919. La organización del espacio editorial. En J. L. de Diego (dir.), Editores y políticas editoriales en Argentina (1880-2000). Buenos Aires/México: Fondo de Cultura Económica, pp. 31-61.

Pla, R. (1967a). La literatura colonial. Capitulo, 1 “Los orígenes (1536-1880)”, agosto, pp. 1-2.

Pla, R. (1967b). El grupo Boedo. Capitulo, 2 "El desarrollo (1880-1940)”, agosto, pp. 29-30.

Pla, R. (1967c). El problema de los períodos en la historia de la literatura. Capitulo, 3 "Los contemporáneos (1940...)", agosto, p. 72.

Prieto, A. (1967). Los desarrollos del pensamiento echeverriano. Alberdi después de Caseros. Elección y parábola de la soledad. Capitulo, 13 "El ensayo en la época romántica", octubre, pp. 296-301.

Rocha Alonso, A. (2006). CEAL visual. El Centro Editor de América Latina y su aporte al diseño editorial”. En M. Bueno y M. A. Taroncher (coord.), Centro editor de América Latina. Capitulos para una historia. Buenos Aires, Argentina: Siglo XXI, pp. 199-206.

Rojas, R. (1922). La literatura argentina. Ensayo filosófico sobre la evolución de la cultura en el Plata, t. IV, Los modernos, Buenos Aires, Argentina: Coni. 
Santos, S. (2006). Historias de la historia. Simpatías y diferencias del proyecto de Capítulo en la historiografía de la literatura argentina (1917-1979). En M. Bueno y M. A. Taroncher (coord.), Centro editor de América Latina. Capitulos para una historia. Buenos Aires, Argentina: Siglo XXI, pp. 63-75.

Sarlo, B. (1967). El marco histórico. Capitulo, 17, “La segunda generación romántica: la poesía”, noviembre, pp. 385-388.

Sarlo, B. (1968). La época. Capitulo, 33 "La poesía en el avance del siglo”, marzo, p. 769.

\section{Notas}

1 La fundación de Eudeba se vincula con otras iniciativas estatales orientadas a promover la ciencia, la industria y la cultura, tales como el INTA (Instituto Nacional de Tecnología Agropecuaria), el INTI (Instituto Nacional de Tecnología Industrial), el INCAA (Instituto Nacional de Cinematografía y Artes Visuales), el CONICET (Consejo Nacional de Investigaciones Científicas y Tecnológicas) y el Fondo Nacional de las Artes. Para mayor información sobre Eudeba como empresa cultural, ver Oscar Fernández (2006).

2 Arturo Illía fue derrocado por las Fuerzas Armadas en la autodenominada "Revolución Argentina" el 28 de junio de 1966. Pocos días después, el general Juan Carlos Onganía se hizo cargo del poder ejecutivo. Apenas transcurrido un mes del golpe de Estado, Onganía, a través de su ministro de Educación, Carlos María Gelly y Obes, intervino las universidades nacionales públicas y decretó el cese de las autonomías universitarias y de su cogobierno, bajo la acusación de que las casas de estudios estaban infiltradas por el comunismo. En el marco de esta situación se dio la Noche de los Bastones Largos, el episodio represivo que motivó la renuncia de varios profesores argentinos.

3 El Centro Editor de América Latina (CEAL) funcionó desde 1966 hasta 1995. Durante ese período publicó cinco mil títulos repartidos en setenta y ocho colecciones de libros y fascículos. Se puede recorrer el itinerario de esas casi tres décadas de actividad gracias al valioso catálogo de sus colecciones compilado por Judith Gociol (2007).

4 La primera colección del CEAL fue la Serie del Encuentro, que apareció a fines de 1966, dirigida por Horacio Achával y Susana Zanetti. Incluyó cuarenta y tres títulos de autores argentinos. Eran generalmente reediciones de: Macedonio Fernández, César Tiempo, Haroldo Conti, Leónidas Barletta, Antonio Di Benedetto, David Viñas, entre otros. La publicación de Capitulo establece relaciones con otras colecciones de CEAL, como Capitulo universal.

5 Desde principios del siglo veinte ya se distribuían libros baratos de forma masiva en kioscos o estaciones de trenes. Por ejemplo, así circularon tres proyectos que, pensados como "bibliotecas de formación", son antecedentes de Capitulo: la Biblioteca de La Nación (lanzada en 1901, dedicada a la literatura universal y de gran éxito en su venta); "La Biblioteca Argentina” dirigida por Ricardo Rojas y "La Cultura Argentina”, a cargo de José Ingenieros (ambos emprendimientos iniciados en 1915). Según Margarita Merbilhaá, estas colecciones "van haciendo suya la demanda del nacionalismo proveniente del Estado y de sectores dominantes de la sociedad” (2014, p. 31) y buscan construir una tradición literaria nacional ofreciendo libros baratos. Para mayor información, ver Margarita Merbilhaá (2014).

6 En 1912, Ricardo Rojas funda la Cátedra de Literatura Argentina y en 1922 el Instituto de Literatura Argentina de la Universidad de Buenos Aires. Para un análisis de Rojas como pedagogo del nacionalismo a cargo de la definición de la identidad nacional, ver Miguel Dalmaroni (2006).

7 Dice Spivacow: "Para muchos, ser editor es un oficio como cualquier otro, como fabricar salchichas que le gusten al público, para que el público las compre, el público las coma, y el público gaste más. Es decir, es buscar los gustos del público, tratar de interpretarlos y ajustarse a ellos fabricando libros, fascículos, para satisfacer ese afán, esa demanda. Para otros, es formar al público. Para mí ha sido siempre formar al público” (Maunás, 1995, p. 105).

8 Cuenta Gregorich: “Aunque nunca llegamos a disponer las cifras de venta exactas, podría afirmarse que se habían superado holgadamente los 150.000 ejemplares semanales, con lo que batíamos a cualquier venta de libros en nuestro país, y entrábamos en insólita competencia con diarios y revistas” (2018, p. 2).

9 Puede consultarse el listado completo de los libros que integraban la Biblioteca Argentina Fundamental del CEAL en el volumen de Judith Gociol (2007). Aclara de Diego: "Si bien la colección estuvo dirigida a recuperar textos clásicos en ediciones económicas, alrededor de 15 títulos, correspondientes a "Los nuevos" fueron de autores contemporáneos; entre otros: Eduardo Mallea, Leopoldo Marechal, Ernesto Sabato, David Viñas y Abelardo Castillo (2019, p. 164).

10 Hacia 1968, Juan José Saer había publicado las novelas Responso (1964) y La vuelta completa (1966), y los libros de cuentos En la zona (1960), Palo y hueso (1965) y Unidad de lugar (1967). Tununa Mercado había publicado Celebrar a la mujer como a una pascua (1967), su primer libro de cuentos.

11 El cuarto tomo de la Historia de la literatura argentina. Ensayo filosófico sobre la evolución de la cultura en el Plata de Ricardo Rojas estudia “Los modernos”, y en el último capítulo, se ocupa de "Las empresas literarias” casi contemporáneas. Incluso, dice Rojas: "mis conclusiones habrán de ser forzosamente provisionales, dado que continuamos viviendo dentro 
del mismo ciclo cultural” (1922, IV, p. 673). Agradezco a Claudia Roman esta observación; su lectura lúcida y sus valiosos comentarios ayudaron a precisar varios aspectos de este trabajo.

12 En otro texto publicado en La Nación, Gregorich se refiere a sí mismo como "coordinador y secretario ejecutivo", mientras que "el director era Roger Pla y el asesor Adolfo Prieto" (2012, p. 2).

13 Oscar "Negro" Díaz fue un diseñador fundamental para el campo editorial argentino. Fue jefe de arte de las editoriales Abril, Eudeba y CEAL. También se ocupó del diseño de La Rosa Blindada, Kapelusz y Libros del Quirquincho. Su modalidad de trabajo era artesanal con imágenes de colores fuertes, de alto impacto (Rocha Alonso, 2006, p. 194).

14 A esta enumeración se deben añadir los géneros literarios. Siguen este criterio: "La prosa romántica: memorias, biografías, historia" ( $\left.n^{\circ} 12\right)$, "El ensayo en la época romántica" ( $\left.n^{\circ} 13\right)$, “La novela moderna: Roberto Arlt" ( ${ }^{\circ}$ 42), "La novela experimental: Leopoldo Marechal” ( $\left.n^{\circ} 47\right)$. En los primeros fascículos introductorios se anticipa la importancia de los géneros por el carácter explicativo de una "Clasificación tradicional de los géneros literarios" (Pla, 1967a, p. 24) y del cuadro sinóptico "Desarrollo de los géneros literarios en la Argentina (1536-1880)” (Pla, 1967a, p, 23). Como señala Claudia Roman, en Capítulo la idea de género no clasifica en estos ejemplos, porque como se advierte en los títulos de los fascículos, cada género específico es, en realidad, un autor. Más bien sirve como muletilla discursiva para que la historia no quede atada a lo biográfico.

15 Esta observación se deriva de la productiva recomendación metodológica de Verónica Delgado: “Señalar el grado de especialización en la práctica en que se inscribe una publicación cultural, literaria, política, artística, etc., e indicar la existencia o inexistencia de una voluntad programática; en el caso en que la hubiere, detallar cómo y en qué sitios puede reconocerse ya sea explícita o indirectamente -en determinados textos" (2015, p. 23). 